\title{
DOCÊNCIA NA CIBERCULTURA
}

CONTRIBUIÇÖES DA OBRA DE PAULO FREIRE

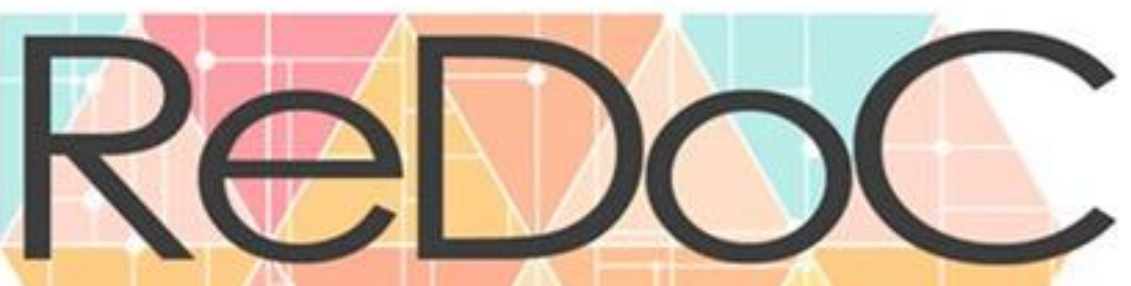

Revista Docência e Cibercultura

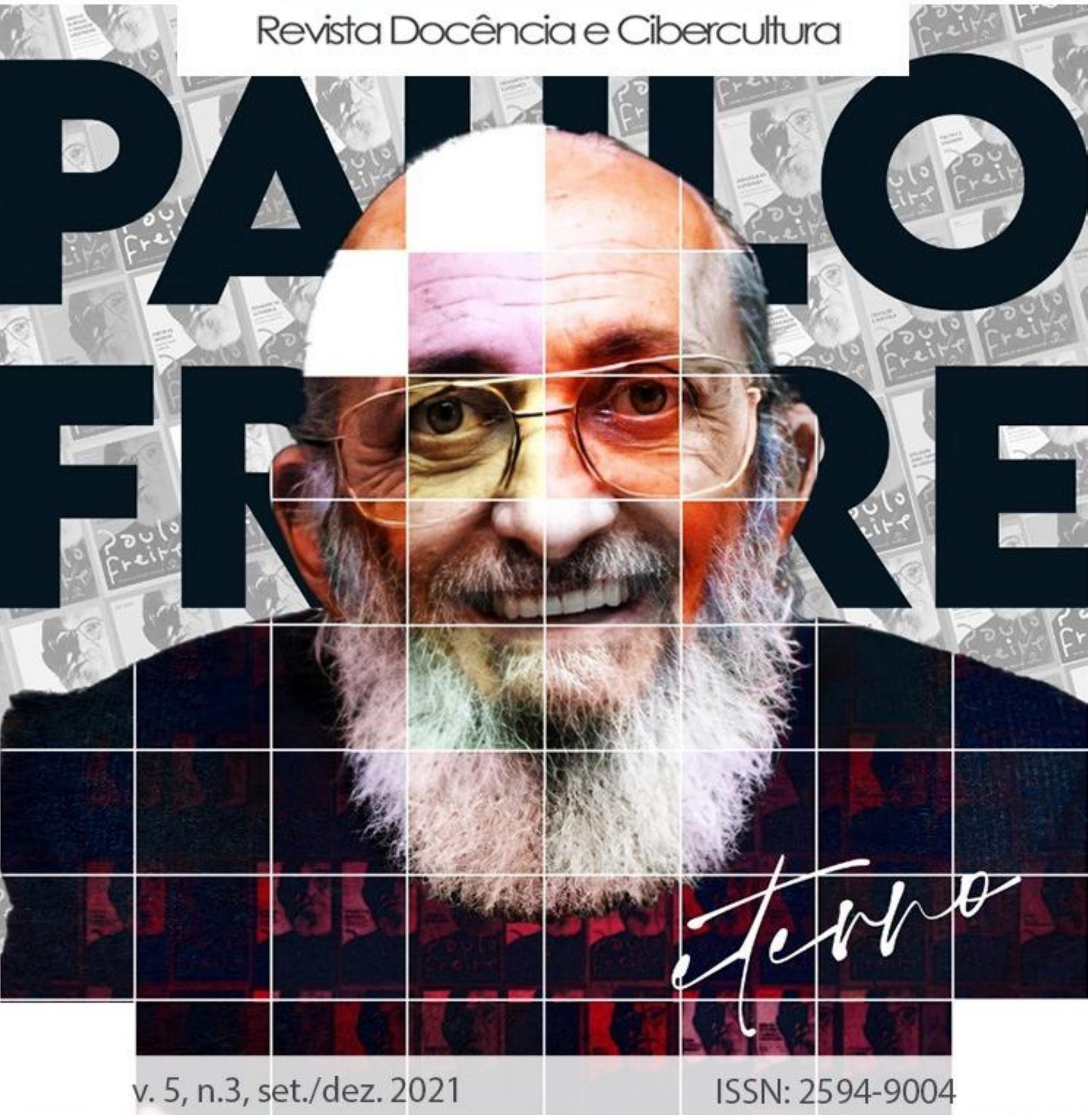




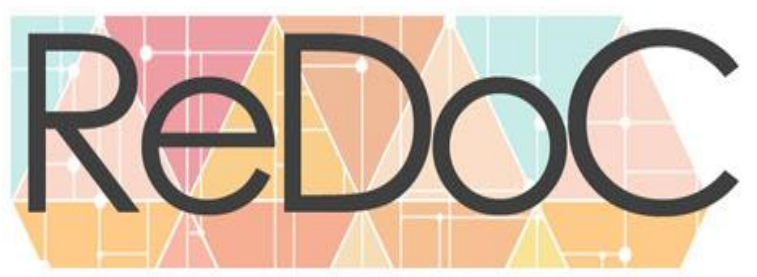

Revista Docência e Cibercultura

\title{
Ficha Técnica - Editorial
}

\author{
Reitor Ricardo Lodi Ribeiro \\ Vice-Reitor Mario Sergio Alves Carneiro \\ Sub-Reitora de Graduação Lincoln Tavares Silva
}

Sub-Reitor de Pós-graduação e Pesquisa Luís Antônio Campinho Pereira da Mota

Sub-Reitora de Extensão e Cultura Cláudia Gonçalves de Lima

Diretor da Faculdade de Educação Washington Dener dos Santos Cunha

Coordenadora do Programa de Pós- Talita Vidal Pereira Graduação em Educação/ ProPed

\author{
Editor-chefe Edméa Oliveira dos Santos \\ Editor-científico Rosemary dos Santos \\ Cristiane Porto \\ Editor-gerente Felipe da Silva Ponte de Carvalho
}

Editor-executivo Tania Lucía Maddalena

Mirian Maia do Amaral

Nome da edição Temática

DOCÊNCIA NA CIBERCULTURA: CONTRIBUIÇÕES DA OBRA DE PAULO FREIRE

Organizadoras da Seção Temática

Edméa Santos (UFRRJ) e Lucila Pesce (UNIFESP)

llustração da capa Wallace Carriço de Almeida

Ana Katia Alves Santos/UFBA

Ana Lucia Gomes da Silva/UNEB

Aristóteles de Paula Berino/UFRRJ

Avaliadoras/es Clarisse de Mendonça e Almeida/UERJ

Edmara Carvalho Novaes/SEEMS

Edméa Santos/UERJ e UFRRJ

Denilson Marques dos Santos/UEPA

n. 3

p. 2 
Revista Docência e Cibercultura

Gerusa do Livramento Carneiro de Moura/Estácio Janaina Cardoso/UERJ

Joselito Manoel de Jesus/UNEB

Handherson Leyltton Costa Damasceno/IF Sertão-PE

Leonardo Zenha Cordeiro/UFPA

Leandro Teofilo de Brito/UFRJ

Lucila Pesce/UNIFESP

Luis Henrique Monteiro de Castro /FAETEC

Luís Paulo Cruz Borges/UERJ

Maristela Midlej Araujo Veloso/UFBA

Rosemary dos Santos/UERJ

Terezinha Fernandes Souza/UFMT

Tiago Ribeiro/ INES

Vittorio Oliveira Lo Bianco/UERJ

Uriel Castellanos Aguirre/UFBA

Zuleide Paiva da Silva/UNEB 


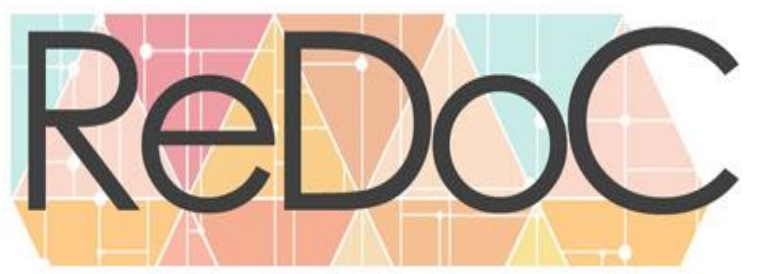

\section{Revista Docência e Cibercultura}

\section{SUMÁRIO}

Paulo Freire vive!

Paulo Freire nas práticas cibereducaticas: narrativas docentes durante a pandemia COVID 19.

Conversando com Paulo Freire - Diálogos dentro e fora do PPGEDUC/UFRRJ

\#PauloFreire100Anos - transformação social e cultura digital: Memórias freirianas nas ações da UNIFESP - UAB.

Dialogando com Paulo Freire e Marielle Franco: um manifesto poético através de uma performance audiovisual.

Educar em tempos de pandemia: desafios da profissão docente

$.40-52$

Práxis na cibercultura: dialógica entre a pedagogia freiriana e as pedagogias feministas...53-83

Autonomia, colaboração, autoria e docência na cibercultura - Questões sob a ótica de Freire e Bernstein

Revisitando os construtos de Paulo Freire para o enfrentamento da docência na crise causada pela pandemia.....

$104-122$

Grupo de estudo: um relato de experiência sobre a mediação virtual durante a pandemia do Covid-19. 123-138

Pessoa surda e autonomia freireana: o ciberespaço como meio de soerguimento $.139-150$

Práticas docentes na cibercultura e o esperançar de professoras na pandemia: possibilidades educativas para tornar o inédito, viável. $.151-174$

Cartas sobre a discência e a docência on-line: uma experiência com Paulo Freire $.175-190$

Contribuições de Paulo Freire para o ensino da leitura e escrita: dimensão linguística. $191-206$

A empatia freireana na alfabetização popular: concepções da cibercultura em tempos de pandemia. 207-221 


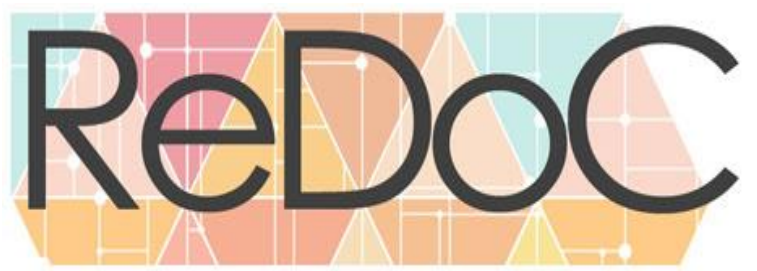

Revista Docência e Cibercultura

Mobilização das habilidades e estratégias metacognitivas por meio dos jogos digitais. $222-242$

Como a comunicação ensina: a experiência do Observatório Qualidade de Vida no Trabalho. 243-257

Práxis docente e currículo em ação: ensino, pesquisa e extensão narrados em três atos. $258-275$

Tecnologias digitais e práticas docentes inovadoras: (re)inventando o estágio supervisionado em letras no contexto de atividades remotas. 276-292

APP-Learning na formação continuada de professores 293-303 


\section{PAULO FREIRE VIVE!}

Felipe Carvalho ${ }^{1}$

Rosemary dos Santos $^{2}$

Começamos esta presente edição da Revista Docência e Cibercultura (ReDoC) comemorando o centenário do pensador-educador-patrono da educação brasileira Paulo Freire. As suas ideias têm inspirado inúmeras pesquisas, teorizações, abordagens didático-pedagógicas e educadoras/es no Brasil e no mundo, e têm contribuído no presente para as discussões que se voltam contra o cibertecnicismo, que efetiva uma abordagem pedagógica "instrucionista, massiva, algoritmizada/automatizada, plataformizada, gamificada, dataficada, uberizada" (PIMENTEL; CARVALHO, 2021, n. p.), que vem tomando forma atualmente em nossa sociedade mediada por tecnologias digitais em rede.

Sabemos que, nas últimas décadas, Paulo Freire vem sendo atacado e desqualificado por múltiplas investidas de forças reacionárias de viés fascista, sob a justificativa de que as suas ideias promovem o comunismo e a doutrinação marxista. Cabe pontuar que essas forças, entre outras, sempre estiveram presentes em nosso contexto, inclusive, em outrora, contribuíram para a prisão e o exílio de Paulo Freire durante a ditadura militar brasileira.

\footnotetext{
${ }^{1}$ Doutor e mestre pelo Programa de Pós-graduação em Educação ProPEd/UERJ. Pesquisador colaborador do grupo de pesquisa GPDOC/UFRRJ. Lattes: http://lattes.cnpq.br/8539464540238508 E-mail: felipesilvaponte@gmail.com

${ }^{2}$ Doutora e Mestre em Educação pela UERJ. Professora Adjunta (FEBF-UERJ). Professora do Programa Proped na Linha de Pesquisa Cotidianos/Redes Educativas/Processos Culturais. Professora do Programa (PPGECC) na Linha de Pesquisa: Educação/Comunicação/Cultura. Vice-coordenadora do GPDOC. Líder do EduCiber. Parecerista Ad Hoc do GT 16, Educação/Comunicação, da ANPED. Parecerista Ad Hoc do ENDIPE. Associada da AbdC. Bolsista JCNE (FAPERJ). Procientista. Atuou 26 anos como professora da Educação Básica no Município de DC/RJ. Atua na área de Educação, com destaque nas seguintes áreas: Educação/Pesquisa/Cibercultura. Formação de Professores. Currículo. Periferias Urbanas. Educação Básica.
} 


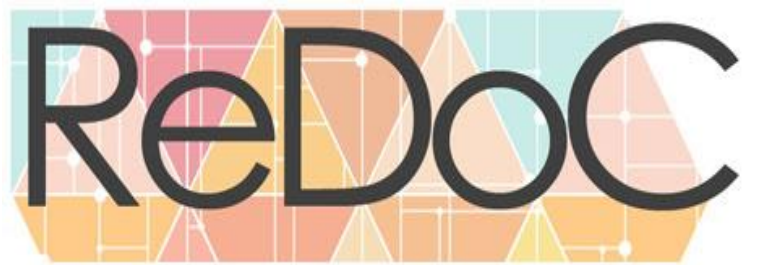

Revista Docência e Cibercultura

Partimos da compreensão de que as ideias de Freire seguem atuais e afiadas, como lâminas de navalha, enfrentando as forças reacionárias e dilatando as possibilidades de pensarfazer uma educação alinhada a modos ético-estético-políticos de condução na vida cotidiana, uma educação como prática de liberdade, uma prática crítica e transformadora de mundo e no mundo.

Iniciamos esta edição com a seção Produções Artísticas, Literárias e Culturais, nela, encontramos os trabalhos: "Conversando com Paulo Freire - Diálogos dentro e fora do PPGEDUC/UFRRJ" escrito por Nathalia de Souza Silva, Edméa Oliveira dos Santos e Rosângela Malachias; e “\#PauloFreire100Anos - transformação social e cultura digital: Memórias freirianas nas ações da UNIFESP - UAB” de autoria Lucila Maria Pesce, Claudia Coelho Hardagh, Luciano Gamez Gamez, Valéria Sperduti Lima, Sylvia Helena S da Silva Batista, Rosângela Aparecida Dantas de Oliveira e Mariângela Graciano; e "Dialogando com Paulo Freire e Marielle Franco: um manifesto poético através de uma performance audiovisual" de Danielle do Nascimento Oliveira Oliveira e Bianca de Menezes Castro da Silva. Em seguida, temos o artigo "Educar em tempos de pandemia: desafios da profissão docente" de Júnior Leandro Gonçalves e Lucila Pesce compondo a seção Ensaios.

Já na seção Temática, contamos com nove artigos, a saber: "Práxis na cibercultura: dialógica entre a pedagogia freiriana e as pedagogias feministas”, escrito por Joselito Manoel de Jesus, Ana Lúcia Gomes da Silva e Zuleide Paiva da Silva; "Autonomia, colaboração, autoria e docência na cibercultura - Questões sob a ótica de Freire e Bernstein” de Clarisse de Mendonça e Almeida, Vittorio Leandro Oliveira Lo Bianco; "Revisitando os construtos de Paulo Freire para o enfrentamento da docência na crise causada pela pandemia" produzido por Marilda Aparecida Behrens, Patricia Lupion Torres e Edna Liz Prigol; "Grupo de estudo: um relato de experiência sobre a mediação virtual durante a pandemia do Covid-19" da autora Geovânia de Souza Andrade Maciel; "Pessoa surda e autonomia freireana: o ciberespaço como meio de soerguimento" de autoria de Jéssica Bittencourt França e Rodrigo Pedro Casteleira; "Práticas docentes na cibercultura e o esperançar de professoras na pandemia: possibilidades 


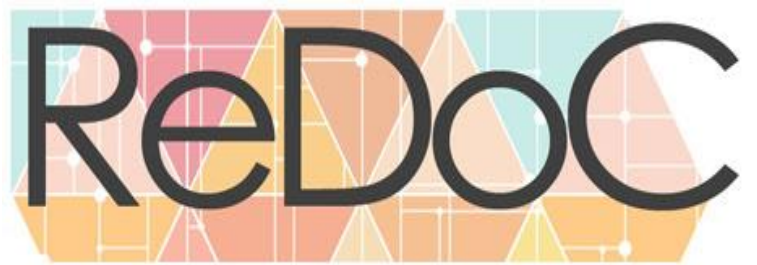

Revista Docência e Cibercultura

educativas para tornar o inédito, viável” abordado por Ana Clara São Thiago, Karolyne Neves da Silva e Luciana Velloso; "Cartas sobre a discência e a docência on-line: uma experiência com Paulo Freire" discutido por Aristóteles de Paula Berino e Talita Cabral da Ponte Carvalho; "Contribuições de Paulo Freire para o ensino da leitura e escrita: dimensão linguística" da autora Jilvania Lima dos Santos Bazzo; e, fechando a seção, "A empatia freireana na alfabetização popular: concepções da cibercultura em tempos de pandemia" de Laurinaldo Félix Nascimento, Luana Priscila Wunsch, Maria Aparecida Fernandes e Maria Batista Leal.

Os artigos: "Mobilização das habilidades e estratégias metacognitivas por meio dos jogos digitais" de autoria de Fernando Silvio Cavalcante Pimentel e Valdick Barbosa Sales Junior; e "Como a comunicação ensina: a experiência do Observatório Qualidade de Vida no Trabalho" escrito por Luiz Carlos dos Santos Ferreira Sacramento, José Antônio Carneiro Leão e Jadirlete Lopes Cabral compõem a seção Fluxo Continuo.

A seção Relato de Experiência traz os trabalhos: "Práxis docente e currículo em ação: ensino, pesquisa e extensão narrados em três atos" de José Alex Soares Santos; e "Tecnologias digitais e práticas docentes inovadoras: (re)inventando o estágio supervisionado em letras no contexto de atividades remotas" escrito por Luciano Santos Xavier, Crizeide Miranda Freire e Antenor Rita Gomes. Fechando a edição, temos a seção de Resumos de Teses e Dissertações, contendo o trabalho "APP-Learning na formação continuada de professores" da autora Eliane Silva Souza.

Esses dezoitos trabalhos apresentados nesta edição discutem diferentes experiências de pensar-fazer a pesquisa acadêmica a partir de diversos pontos de vista, e trazem, principalmente, novas maneiras de "aprenderensinar em rede" (SANTOS; RIBEIRO; CARVALHO, 2021) em sintonia com o nosso tempo. Finalizamos a apresentação destacando que a ReDoC está disponível em suporte digital em rede. É um periódico quadrimestral, de orientação pluralista, voltado à discussão de produções originais elaboradas pela comunidade científica nacional e internacional, da área de Educação e do Ensino e suas interfaces com a cibercultura, identidade, diferença. A ReDOC aceita Artigos, Relatos de Experiência, Pontos 


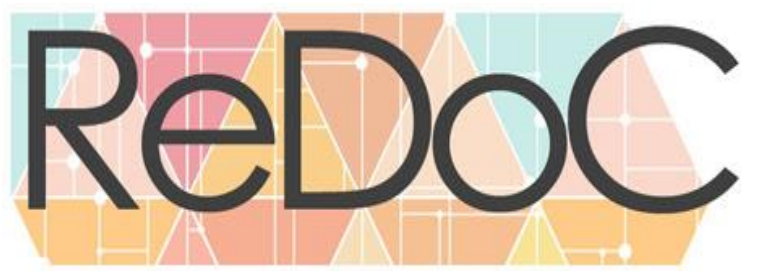

Revista Docência e Cibercultura

de Vista, Resenhas, Ensaios, Entrevistas, Conversas, Bibliografias Comentadas, Produções Artísticas e Culturais, Vídeo-Pesquisa, e Resumos de Dissertações e de Teses.

Tenham uma excelente leitura a todas, todes, todxs e todos!

\section{Referências}

ALMEIDA, Clarisse de Mendonça; LO BIANCO, Vittorio Leandro Oliveira. Autonomia, colaboração, autoria e docência na cibercultura - Questões sob a ótica de Freire e Bernstein. Revista Docência e Cibercultura, v. 5, n. 3, set.-dez., 2021, p. 84-103. DOI: https://doi.org/10.12957/redoc.2021.60097

BAZZO, Jilvania Lima dos Santos. Contribuições de Paulo Freire para o ensino da leitura e escrita: dimensão linguística. Revista Docência e Cibercultura, v. 5, n. 3, set.-dez., 2021, p. 191-206. DOI: https://doi.org/10.12957/redoc.2021.60147

BEHRENS, Marilda Aparecida; TORRES, Patricia Lupion; PRIGOL, Edna Liz. Revisitando os construtos de Paulo Freire para o enfrentamento da docência na crise causada pela pandemia. Revista Docência e Cibercultura, v. 5, n. 3, set.-dez., 2021, p. 104-122. DOI: https://doi.org/10.12957/redoc.2021.60106

BERINO, Aristóteles de Paula; CARVALHO, Talita Cabral da Ponte. Cartas sobre a discência e a docência on-line: uma experiência com Paulo Freire. Revista Docência e Cibercultura, v. 5, n. 3, set.-dez., 2021, p. 175-190. DOI: https://doi.org/10.12957/redoc.2021.60136

FRANÇA, Jéssica Bittencourt; CASTELEIRA, Rodrigo Pedro. Pessoa surda e autonomia freireana: o ciberespaço como meio de soerguimento. Revista Docência e Cibercultura, v. 5, n. 3, set.-dez., 2021, p. 139-150. DOI: https://doi.org/10.12957/redoc.2021.60056

GONÇALVES Júnior Leandro; e PESCE, Lucila. Educar em tempos de pandemia: desafios da profissão docente. Revista Docência e Cibercultura, v. 5, n. 3, set.-dez., 2021, p. 40-52. DOI: https://doi.org/10.12957/redoc.2021.61398

JESUS, Joselito Manoel de; SILVA, Ana Lúcia Gomes da; SILVA, Zuleide Paiva da. Práxis na cibercultura: dialógica entre a pedagogia freiriana e as pedagogias feministas. Revista Docência e Cibercultura, v. 5, n. 3, set.-dez., 2021, p. 53-83. DOI: https://doi.org/10.12957/redoc.2021.60085 


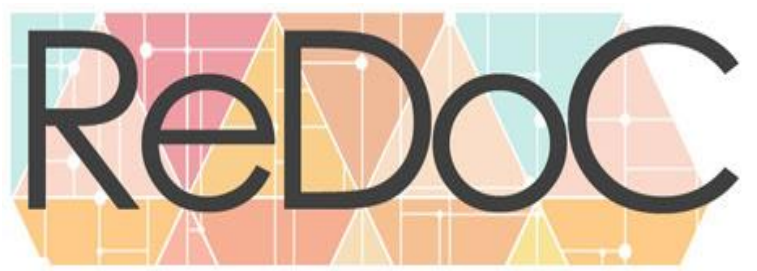

Revista Docência e Cibercultura

MACIEL, Geovânia de Souza Andrade. Grupo de estudo: um relato de experiência sobre a mediação virtual durante a pandemia do Covid-19. Revista Docência e Cibercultura, v. 5, n. 3, set.-dez., 2021, p. 123-138. DOI: https://doi.org/10.12957/redoc.2021.60080

NASCIMENTO, Laurinaldo Félix; WUNSCH, Luana Priscila; FERNANDES, Maria Aparecida; LEAL, Maria Batista. A empatia freireana na alfabetização popular: concepções da cibercultura em tempos de pandemia. Revista Docência e Cibercultura, v. 5, n. 3, set.-dez., 2021, p. 207-201. DOI: https://doi.org/10.12957/redoc.2021.61235

OLIVEIRA, Danielle do Nascimento; SILVA, Bianca de Menezes Castro da. Dialogando com Paulo Freire e Marielle Franco: um manifesto poético através de uma performance audiovisual. Revista Docência e Cibercultura, v. 5, n. 3, set.-dez., 2021, p. 31-39. DOI: https://doi.org/10.12957/redoc.2021.61587

PESCE, Lucila Maria; HARDAGH, Claudia Coelho; GAMEZ, Luciano; LIMA, Valéria Sperduti; BATISTA, Sylvia Helena S da Silva; OLIVEIRA, Rosângela Aparecida Dantas de; GRACIANO, Mariângela. \#PauloFreire100Anos - transformação social e cultura digital: Memórias freirianas nas ações da UNIFESP - UAB. Revista Docência e Cibercultura, v. 5, n. 3, set.-dez., 2021, p. 27-30. DOI: https://doi.org/10.12957/redoc.2021.62855

PIMENTEL, Fernando Silvio Cavalcante; JUNIOR, Valdick Barbosa Sales. Mobilização das habilidades e estratégias metacognitivas por meio dos jogos digitais. Revista Docência e Cibercultura, v. 5, n. 3, set.-dez., 2021, p. 222-242. DOI: https://doi.org/10.12957/redoc.2021.61036

PIMENTEL, Mariano; CARVALHO, Felipe da Silva Ponte. Instrução (re)programada, máquinas (digitais em rede) de ensinar e a pedagogia (ciber)tecnicista. SBC Horizontes, jun. 2021. Disponível em: http://horizontes.sbc.org.br/index.php/2021/07/maquinas-de-ensinar. Acesso em: 08 out. 2021.

SACRAMENTO, Luiz Carlos dos Santos Ferreira; LEÃO, José Antônio Carneiro; CABRAL, Jadirlete Lopes. Como a comunicação ensina: a experiência do Observatório Qualidade de Vida no Trabalho. Revista Docência e Cibercultura, v. 5, n. 3, set.-dez., 2021, p. 243-257. DOI: https://doi.org/10.12957/redoc.2021.60139

SANTOS, Rosemary; RIBEIRO, Rodrigues Fernandes, CARVALHO, Felipe da Silva Ponte. Educação Online: aprenderensinar em rede. In: SANTOS, Edméa Oliveira; SAMPAIO, Fábio; PIMENTEL, Mariano (Org.). Informática na Educação: fundamentos e práticas. Porto Alegre: Sociedade Brasileira de Computação, 2021. (Série Informática na Educação CEIE-SBC, v.1) Disponível online: https://ieducacao.ceie-br.org///educacaoonline/. Acesso em: 08 out. 2021. 


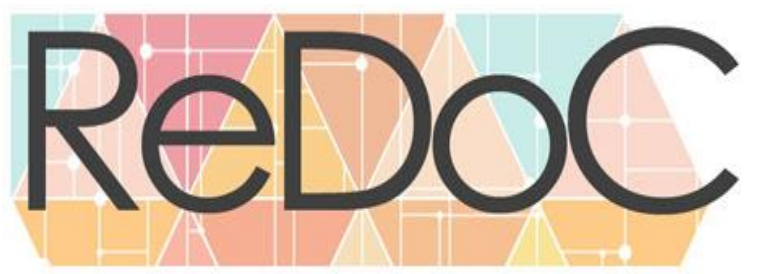

Revista Docência e Cibercutura

SÃO THIAGO, Ana Clara; SILVA, Karolyne Neves da; VELlOSO, Luciana. Práticas docentes na cibercultura e o esperançar de professoras na pandemia: possibilidades educativas para tornar o inédito, viável. Revista Docência e Cibercultura, v. 5, n. 3, set.-dez., 2021, p. 151-174. DOI: https://doi.org/10.12957/redoc.2021.60120

SILVA, Nathalia de Souza; SANTOS, Edméa Oliveira dos; MALACHIAS, Rosângela. Conversando com Paulo Freire - Diálogos dentro e fora do PPGEDUC/UFRRJ. Revista Docência e Cibercultura, v. 5, n. 3 , set.-dez., 2021, p. 21-26. DOI: https://doi.org/10.12957/redoc.2021.62823

SANTOS, José Alex Soares. Práxis docente e currículo em ação: ensino, pesquisa e extensão narrados em três atos. Revista Docência e Cibercultura, v. 5, n. 3, set.-dez., 2021, p. 258-275. DOI: https://doi.org/10.12957/redoc.2021.5629

SOUZA, Eliane Silva. APP-Learning na formação continuada de professores. Revista Docência e Cibercultura, v. 5, n. 3, set.-dez., 2021, p. 293-303. DOI: https://doi.org/10.12957/redoc.2021.59147

XAVIER, Luciano Santos; FREIRE, Crizeide Miranda; e GOMES, Antenor Rita. Tecnologias digitais e práticas docentes inovadoras: (re)inventando o estágio supervisionado em letras no contexto de atividades remotas. Revista Docência e Cibercultura, v. 5, n. 3, set.-dez., 2021, p. 276-292. DOI: https://doi.org/10.12957/redoc.2021.61093

Este é um artigo de acesso aberto distribuído sob os termos da Licença Creative Commons Atribuição Não Comercial-Compartilha Igual (CC BY-NC- 4.0), que permite uso, distribuição e reprodução para fins não comerciais, com a citação dos autores e da fonte original e sob a mesma licença. 